\title{
Diagnostic accuracy of the interferon-gamma release assay in acquired immunodeficiency syndrome patients with suspected tuberculosis infection: a meta-analysis
}

\author{
Hao Chen ${ }^{1} \cdot$ Atsushi Nakagawa $^{2} \cdot$ Mikio Takamori $^{3} \cdot$ Seitarou Abe $^{4}$. Daisuke Ueno ${ }^{5}$ Nobuyuki Horita ${ }^{6} \cdot$ Seiya Kato $^{7}$. \\ Nobuhiko Seki ${ }^{1,8}$
}

Received: 2 January 2022 / Accepted: 22 February 2022 / Published online: 6 March 2022

(c) The Author(s) 2022

\begin{abstract}
Purpose The diagnostic accuracy of the interferon-gamma release assay (IGRA) in immunosuppressed patients remains unclear.

Methods A systematic review and meta-analysis were performed for diagnostic test accuracy of IGRA in tuberculosis (TB) infection among people living with HIV (PLWHIV). Summary estimates of sensitivity and specificity were calculated using both univariate and bivariate models.

Results The meta-analysis included 45 of the 1,242 first-screened articles. The total number of PLWHIV was 6,525; 3,467 had TB disease, including 806 cases of LTBI and 2,661 cases of active TB. The overall diagnostic odds ratio (DOR) of IGRA in the diagnosis of TB disease was 10.0 (95\% confidence interval (CI) 5.59, 25.07), with an area under the curve (AUC) of 0.729. The DOR was better for QFT (14.2 (95\%CI 4.359, 46.463)) than T-SPOT (10.0 (95\%CI 3.866 26.033)). The sensitivity and specificity of QFT and T-SPOT were 0.663 (95\%CI 0.471, 0.813), 0.867 (95\%CI 0.683 0.942), and 0.604 (95\%CI $0.481,0.715), 0.862(95 \%$ CI $0.654,0.954)$, respectively, in the bivariate model. The sensitivity of IGRA in the diagnosis of LTBI was 0.64 (95\%CI 0.61, 0.66).

Conclusion IGRA was useful in the diagnostic of TB disease in PLWHIV, and QFT showed a better tendency of DOR than T-SPOT. IGRA showed a limited effect to rule out LTBI in PLWHIV.
\end{abstract}

Keywords Interferon-gamma release assay $\cdot$ Tuberculosis $\cdot$ People living with HIV $\cdot$ Sensitivity $\cdot$ Specificity

\section{Introduction}

Individuals infected with Mycobacterium tuberculosis (Mtb) may develop symptoms and signs of active tuberculosis (ATB) or may stay in latent tuberculosis infection (LTBI) which have

All authors contributed equally to this article.

Nobuhiko Seki

nseki@med.teikyo-u.ac.jp

1 Department of Internal Medicine, Teikyo University Graduate School of Medicine, Tokyo, Japan

2 Department of Respiratory, Kobe City Medical Center General Hospital, Kobe, Japan

3 Department of Respiratory, Tokyo Metropolitan Tama Medical Center, Tokyo, Japan

4 Department of Respiratory, Niigata Prefectural Shibata Hospital, Niigata, Japan no clinical evidence of the active disease [1]. Mtb is the leading cause of opportunistic infection involved in the death of people living with human immunodeficiency virus (PLWHIV) [2], while the diagnosis is further problematic due to its paucibacillary nature. In addition, human immunodeficiency virus (HIV) infection may cause respiratory problems that can

5 Department of Emergency Medicine, Kawasaki Medical School Hospital, Okayama, Japan

6 Department of Pulmonology, Yokohama City University, Yokohama, Japan

7 Research Institute of Tuberculosis, Japan Anti-Tuberculosis Association, Tokyo, Japan

8 Department of Oncology, Teikyo University Hospital, 2-11-1 Kaga, Itahashi, Tokyo 173-8606, Japan 
mimic tuberculosis clinically and/or radiologically. An early diagnosis in this group is thus important.

Until recently, the tuberculin skin test (TST) has been the only method to test for latent infection with Mtb. The TST has well-known strengths and limitations by measuring the delayed type hypersensitivity response to intradermal injection of purified protein derivative [3]. Whereas the TST encompasses antigens recognized by a vast pool of circulating $\mathrm{T}$ lymphocytes, the two interferon-gamma (IFN- $\gamma$ ) release assays (IGRAs), the QuantiFERON-TB® ${ }^{\circledR}$ assay (Cellestis Limited, Victoria, Australia) and T-SPOT-TB® (Oxford Immunotec, London, UK), focus on interferon-gamma responses to epitopes from two specific antigens which is associated with Mtbs complex, namely early secretory antigenic-6 (ESAT-6) and culture filtrate protein-10 (CFP-10). No direct tests for LTBI, and therefore no gold standards, are available with which to compare LTBI test characteristics [4]. IGRA rather than TST was recommended by the Centers for Disease Control and Prevention (CDC) in individuals 5 years or older upon the likelihood of infection with Mtb and the likelihood of progression to TB disease if infected [1].

For the IGRA or TST to reliably rule out a diagnosis of Mtb infection and thus TB disease, the sensitivity of the test must be very high (>95\%) [5]. The sensitivity and specificity of IGRAs compared with the TST in active TB have been examined in several studies, varying in value and quality [6]. IGRA have a better predictive ability than tuberculin skin tests. Individuals who are positive on an IGRA might benefit from preventive treatment, but those who are positive by TST probably will not [7]. The pooled sensitivity (95\% confidence interval (CI)) of QFT and T-SPOT, T-SPOT, and TST was: $80 \%(75-84 \%), 81 \%(78-84 \%)$, and $65 \%$ (61-68\%), respectively, in the previous meta-analysis and the sensitivity of IGRAs was too low to support their use as rule-out tests for active TB [8]. PLWHIV represents a group at higher risk of reactivating LTBI. Furthermore, immunosuppression can lower the sputum bacillary load, making the diagnosis of ATB by microscopy more challenging [9]. In PLWHIV, the performance of IGRAs is not as reliable as previously measured in the general population [10]. The diagnostic accuracy of IGRAs in PLWHIV was necessary to answer the question of timely TB diagnosis and the medical community is cautious in interpretation of IGRAs' results. This study aimed to evaluate the contribution of IGRAs to the diagnosis of TB disease in PLWHIV.

\section{Methods}

\section{Study overview}

This systematic review and meta-analysis of diagnostic test accuracy was prepared following standard guidelines for systematic reviews of diagnostic test accuracy and registered on the website of the University Hospital Medical Information Network Clinical Trials Registration (UMIN000045715) [11, 12]. Due to the nature of this study, approval of the Institutional Review Board was waived.

\section{Study search}

Four major online databases, PubMed, Web of Science, Cochrane, and Embase, were searched (September 30, 2021). The following search strategy was used for PubMed: (((interferon- $\gamma$ release assay) OR (interferon-gamma release assay)) OR (IGRA)) AND ((((HIV) OR (Human Immunodeficiency Virus)) OR (acquired immunodeficiency syndrome)) OR (AIDS)).

Two authors (HC and AN) independently screened the titles and abstracts and carefully evaluated the full text to select eligible articles; in cases of discrepancy, they reached a consensus through discussion. Review articles and included original articles were hand-searched (HC and AN) for additional research papers that met the inclusion criteria.

\section{Study selection}

Full articles, brief reports, and conference abstracts published in any language that provided data for sensitivity and specificity of IGRA to diagnose TB were included. An article that provided data of both sensitivity and specificity was included in the bivariate analysis [11]. An article that provided data of either sensitivity or specificity was included in the univariate analysis. A case-control study design that consisted of patients with or without TB disease was accepted, though a case-control design may be considered to have a risk of bias according to Quality Assessment of Diagnostic Accuracy Studies-2 (QUADAS-2) [13].

The target population was PLWHIV with TB and LTBI co-infection. The diagnostic criterion for ATB was sputum culture-positive for TB or detection of nucleic acids, both DNA and RNA, which are specific to Mycobacterium tuberculosis, by amplification techniques such as polymerase chain reaction. LTBI is a subclinical mycobacterial infection defined on the basis of cellular immune response to mycobacterial antigens [14]. TST and IGRA are currently used to establish the diagnosis of LTB. The diagnostic criteria for LTBI were either positive on IGRA or TST or a radiograph without clinical findings of active TB. The target IGRA test included T-SPOT and QFT.

\section{Outcomes}

Sensitivity, specificity, area under the curve (AUC), and the diagnostic odds ratio were evaluated in studies with both sensitivity and specificity. Univariate analysis was conducted 
for studies with either sensitivity or specificity. Only data from the 3rd and 4th generations of QFT (QuantiFERONTB-Gold In-Tube and QuantiFERON-plus) were included for test accuracy in this meta-analysis. Studies with test accuracy of the T-SPOT were all enrolled in this analysis. Indeterminate IGRA results were classified as false-negative results.

\section{Data extraction}

Two review authors, $\mathrm{HC}$ and AN, independently extracted data, including the name of the first author, publication year, publication country, numbers of patients with positive results, numbers of patients evaluated, and QUADAS-2-related information. Risk of bias was appraised by QUADAS-2 in each study [13].

\section{Statistics}

A bivariate model was used to obtain pooled sensitivity and specificity and to draw a summary receiver-operating characteristic curve (SROC) [15]. The diagnostic odds ratio (DOR) was obtained by the DerSimonian-Laird random model. The DOR was calculated by the "madauni" command ("netmeta" package of R project, Gerta Rücker, Denmark). Sensitivity, specificity, and AUC were pooled by the "reitsma" command ("netmeta" package of R project, Gerta Rücker, Denmark). AUCs were interpreted as follows: $\geq 0.97$, excellent; $0.93-0.96$, very good; $0.75-0.92$, good; and $0.5-0.74$, fair [16]. The threshold for significance was set at 0.05 . Heterogeneity evaluated using $I^{2}$ statistics was interpreted as follows: $I^{2}=0 \%$, no heterogeneity; $I^{2}>0 \%$ but $<25 \%$, minimal heterogeneity; $I^{2} \geq 25 \%$ but $<50 \%$, mild heterogeneity; $I^{2} \geq 50 \%$ but $<75 \%$, moderate heterogeneity; and $I^{2} \geq 75 \%$, strong heterogeneity [17].

\section{Results}

\section{Study search and study characteristics}

A total of 1,242 articles, including 1,239 articles through database search and 3 articles by hand search, were identified; 937, 192, and 47 articles were left after removing duplication, screening, and full-article reading, respectively (Supplementary Figure S1). Finally, 45 reports, comprising 42 full-length articles and 3 conference abstracts, were included (Table 1) [2, 5, 18-60]. All were written in English. Prospective study designs were adopted in 34 articles, and the other 11 were retrospective studies. Of the 47 reports, six were from South Africa, five were from the USA, four were from China, Italy, and the UK, and two were from Brazil and India. Of the 6,525 PLWHIV were enrolled in this study, 3,467 had TB disease, including 806 cases of LTBI and 2,661 cases of ATB. Nine studies discussed diagnostic accuracy including both T-SPOT and QFT, and 22 and 12 studies discussed the test accuracy of only the QFT or the T-SPOT, respectively. Only five studies discussed test accuracy in children, and two studies checked IGRAs in all populations. The remaining 38 studies checked IGRAs in adults, including two studies that checked IGRAs in women only.

\section{Diagnostic accuracy of IGRAs in TB}

Nineteen studies checked the diagnostic accuracy of IGRAs with both sensitivity and specificity. Thirty-nine studies checked the sensitivity of T-SPOT or QFT in PLWHIV with suspected TB. The univariate analysis of IGRAs in PLWHIV showed sensitivity and specificity of 0.65 (95\% CI $0.63,0.66)$ and 0.92 (95\% CI 0.91, 0.93), respectively (Fig. 1).

\section{Diagnostic accuracy of IGRAs in ATB}

The diagnostic accuracy of IGRAs in ATB was conducted in 49 studies, including in 5,430 participants. On univariate analysis, the sensitivity and specificity were $0.66(95 \% \mathrm{CI}$ $0.63,0.68)$ and $0.92(95 \% \mathrm{CI} 0.91,0.93)$, respectively (Supplementary Figure S2). On bivariate analysis of the test accuracy of IGRAs in 18 studies, the DOR was 11.84 (95\%CI 5.59, 25.07; $I^{2}=0 \%$ ), with AUC of 0.779 . This AUC value suggests that IGRA had "good" diagnostic test accuracy for TB disease (Fig. 2) [16]. Using the data from 45 studies of 7,120 specimens, the summary estimates of sensitivity and specificity were 0.631 (95\%CI $0.523,0.727)$ and 0.866 (95\% CI $0.744,0.934)$, respectively.

\section{Diagnostic accuracy of IGRAs in LTBI}

Since there was no gold standard to diagnose LTBI, seven studies discussed the sensitivity of IGRA in PLWHIV with different diagnostic standards. Five studies defined LTBI by LTBI risk and at least one positive test (TST or IGRA), without clinical evidence of active TB. Two studies calculated sensitivity from supposed presence of LTBI. The univariate analysis yielded a sensitivity of $0.64(95 \%$ CI $0.61,0.66)$ in 1,267 patients (Supplementary Figure S3).

\section{Diagnostic accuracy of QFT in ATB}

Data of 2,519 samples from nine reports suggested a DOR of 14.2 (95\%CI 4.36, 46.46; $I^{2}=0 \%$ ) and an AUC of 0.822 , which means that QFT had "good" diagnostic test accuracy for TB disease (Fig. 3). The summary estimates of sensitivity and specificity were 0.663 (95\% CI 0.471 , 0.813 ) and 0.867 (95\% CI 0.6830 .942$)$, respectively. The univariate analyses showed sensitivity and specificity of 
Table 1 Background characteristics of enrolled studies

\begin{tabular}{|c|c|c|c|c|c|c|c|c|}
\hline Author/year & Country & Types of TB & Type of article & Nature of study & Adult & IGRA & TB patients & All patients \\
\hline Aabye 2009 & Tanzania & AT & FA & Retro & Adult & QFT-GIT & 161 & 161 \\
\hline Adams 2019 & South Africa & LTBI & FA & Retro & Adult & Q\&T & 496 & 496 \\
\hline Cai 2014 & China & AT & FA & Retro & Adult & T-SPOT & 100 & 100 \\
\hline Cattamanchi 2010 & USA & AT & FA & pros & Adult & T-SPOT & 112 & 212 \\
\hline Chee 2008 & Singapore & AT & FA & retro & Adult & Q\&T & 280 & 280 \\
\hline Chen 2011 & China & AT & FA & pros & Adult & T-SPOT & 38 & 147 \\
\hline Clark 2007 & UK & AT & FA & pros & Adult & T-SPOT & 30 & 30 \\
\hline Davies 2009 & South Africa & AT & FA & pros & Children & T-SPOT & 60 & 109 \\
\hline Dheda 2009 & South Africa & AT & FA & pros & Adult & Q\&T & 20 & 20 \\
\hline Elzi 2011 & Switzerland & LTBI & FA & pros & Adult & T-SPOT & 64 & 64 \\
\hline Fujita 2011 & Japan & AT & FA & pros & Adult & QFT-GIT & 9 & 107 \\
\hline Garcia-Gasalla 2013 & Spain & AT & FA & pros & Adult & QFT-GIT & 118 & 118 \\
\hline Hormi 2018 & France & AT & FA & pros & Children & QFT-GIT & 24 & 24 \\
\hline Idh 2010 & Sweden & AT & FA & pros & Adult & QFT-GIT & 69 & 69 \\
\hline Jiang 2009 & China & AT\&LTBI & FA & pros & Adult & T-SPOT & 100 & 100 \\
\hline Jonnalagadda 2013 & USA & AT & FA & retro & Adult(W) & T-SPOT & 9 & 9 \\
\hline Kabeer 2011 & India & AT & FA & pros & Adult & QFT-GIT & 105 & 105 \\
\hline Kaswandani 2018 & Indonesia & TB & $\mathrm{CA}$ & retro & Children & QFT-GIT & 10 & 10 \\
\hline Khawcharoenporn 2015 & Thailand & LTBI & FA & pros & Adult & QFT-GIT & 36 & 36 \\
\hline Klautau 2018 & Brazil & LTBI & FA & retro & Adult & QFT-GIT & 84 & 84 \\
\hline Kussen 2016 & Brazil & LTBI & FA & pros & Adult & QFT-GIT & 25 & 25 \\
\hline LaCourse 2017 & USA & AT & FA & pros & Adult (W) & QFT-GIT & 100 & 100 \\
\hline Lavender 2011 & UK & AT & $\mathrm{CA}$ & retro & Adult & QFT-GIT & 66 & 326 \\
\hline Lee 2019 & Korea & $\mathrm{TB}$ & FA & pros & Adult & T-SPOT & 25 & 62 \\
\hline Legesse 2010 & Ethiopia & AT & FA & pros & Adult & QFT-GIT & 50 & 50 \\
\hline Leidl 2010 & Uganda & AT & FA & retro & Adult & Q\&T & 19 & 19 \\
\hline ling 2011 & Canada & AT & FA & pros & Adult & Q\&T & 127 & 127 \\
\hline Lundtoft 2017 & Ghana & AT & FA & pros & Children & QFT-GIT & 25 & 25 \\
\hline Markova 2009 & Bulgaria & AT & FA & pros & Adult & Q\&T & 13 & 90 \\
\hline Oni 2010 & UK & AT & FA & pros & Adult & T-SPOT & 85 & 85 \\
\hline Petruccioli 2020 & Italy & AT & FA & pros & Adult & QFT-plus & 32 & 32 \\
\hline Pettit 2020 & USA & LTBI & FA & pros & All & Q\&T & 81 & 1520 \\
\hline Raby 2008 & Zambia & AT & FA & pros & Adult & QFT-GIT & 96 & 96 \\
\hline Rangaka 2012 & South Africa & LTBI & FA & pros & Adult & QFT-GIT & 50 & 50 \\
\hline Sanogo 2020 & Burkina & AT & FA & pros & Children & QFT-GIT & 29 & 58 \\
\hline Sattah 2012 & USA & AT & CA & retro & Adult & T-SPOT & 9 & 9 \\
\hline Sauzullo 2010 & Italy & AT & FA & pros & Adult & QFT-GIT & 30 & 194 \\
\hline Sauzullo 2014 & Italy & AT & FA & pros & Adult & QFT-GIT & 44 & 44 \\
\hline Stavri 2009 & Romania & AT & FA & pros & All & QFT-GIT & 36 & 36 \\
\hline Takwoingi 2019 & UK & AT & FA & retro & Adult & Q\&T & 385 & 911 \\
\hline Tsiouris 2006 & South Africa & AT & FA & pros & Adult & QFT-GIT & 36 & 36 \\
\hline Vanini 2012 & Italy & AT & FA & pros & Adult & QFT-GIT & 58 & 58 \\
\hline Veldsman 2009 & South Africa & AT & FA & pros & Adult & QFT-GIT & 30 & 60 \\
\hline Vincenti 2007 & India & AT & FA & pros & Adult & Q\&T & 45 & 111 \\
\hline Yu 2013 & China & AT & FA & pros & Adult & T-SPOT & 46 & 120 \\
\hline
\end{tabular}

$T B$ tuberculosis disease, $A T$ active TB; $L T B I$ latent tuberculosis infection; IGRA interferon-gamma release assay, QFT-GIT QuantiFERON-TBGold In-Tube, $T$-SPOT T-SPOT.TB, $Q \& T$ QuantiFERON-TB-Gold In-Tube and T-SPOT.TB 


\section{Study}

Aabye 2009

Adams 2019 (Q)

Adams 2019 (T)

Cai 2014

Cattamanchi 2010

Chee 2008 (Q)

Chee 2008 (T)

Chen 2011

Clark 2007

Davies 2009

Dheda 2009 (Q)

Dheda 2009 (T)

Elzi 2011

Fujita 2011

Garcia-Gasalla 2013

Hormi 2018

Idh 2010

Jiang 2009 (Q)

Jiang 2009 (T)

Jonnalagadda 2013

Kabeer 2011

Kaswandani 2018

Khawcharoenporn 2015

Klautau 2018

Kussen 2016

LaCourse 2017

Lavender 2011

Lee 2019

Legesse 2010

Leidl 2010 (Q)

Leidl $2010(\mathrm{~T})$

ling $2011(\mathrm{Q})$

ling $2011(T)$

Lundtoft 2017

Markova 2009 (Q)

Markova 2009 (T)

Oni 2010

Petruccioli 2020

Pettit 2020 (Q)

Pettit 2020 (T)

Raby 2008

Rangaka 2012

Sanogo 2020

Sattah 2012

Sauzullo 2010

Sauzullo 2014

Stavri 2009

Takwoingi 2019 (Q)

Takwoingi 2019 (T)

Tsiouris 2006

Vanini 2012

Veldsman 2009

Vincenti 2007 (Q)

Vincenti 2007 (T)

Yu 2013

$\begin{array}{rrrrr}\text { TP } & \text { FP } & \text { FN } & \text { TN } & \text { Sensitivity (95\% Cl) } \\ 44 & 0 & 9 & 0 & 0.83[0.70,0.92] \\ 324 & 0 & 172 & 0 & 0.65[0.61,0.70] \\ 277 & 0 & 188 & 0 & 0.60[0.55,0.64] \\ 59 & 0 & 41 & 0 & 0.59[0.49,0.69] \\ 61 & 34 & 23 & 40 & 0.73[0.62,0.82] \\ 4 & 0 & 3 & 0 & 0.57[0.18,0.90] \\ 7 & 0 & 0 & 0 & 1.00[0.59,1.00] \\ 13 & 11 & 22 & 86 & 0.37[0.21,0.55] \\ 27 & 0 & 3 & 0 & 0.90[0.73,0.98] \\ 29 & 7 & 31 & 42 & 0.48[0.35,0.62] \\ 1 & 0 & 4 & 0 & 0.20[0.01,0.72] \\ 5 & 0 & 0 & 0 & 1.00[0.48,1.00] \\ 25 & 0 & 18 & 0 & 0.58[0.42,0.73] \\ 5 & 1 & 3 & 89 & 0.63[0.24,0.91] \\ 12 & 0 & 1 & 0 & 0.92[0.64,1.00] \\ 2 & 0 & 5 & 0 & 0.29[0.04,0.71] \\ 26 & 0 & 10 & 0 & 0.72[0.55,0.86] \\ 21 & 0 & 11 & 0 & 0.66[0.47,0.81] \\ 46 & 0 & 22 & 0 & 0.68[0.55,0.78] \\ 7 & 0 & 2 & 0 & 0.78[0.40,0.97] \\ 68 & 0 & 19 & 0 & 0.78[0.68,0.86] \\ 5 & 0 & 5 & 0 & 0.50[0.19,0.81] \\ 20 & 0 & 16 & 0 & 0.56[0.38,0.72] \\ 75 & 0 & 9 & 0 & 0.89[0.81,0.95] \\ 21 & 0 & 4 & 0 & 0.84[0.64,0.95] \\ 34 & 0 & 50 & 0 & 0.40[0.30,0.52] \\ 50 & 31 & 16 & 229 & 0.76[0.64,0.85] \\ 20 & 5 & 5 & 32 & 0.80[0.59,0.93] \\ 13 & 0 & 6 & 0 & 0.68[0.43,0.87] \\ 13 & 0 & 6 & 0 & 0.68[0.43,0.87] \\ 17 & 0 & 0 & 0 & 1.00[0.80,1.00] \\ 29 & 0 & 14 & 0 & 0.67[0.51,0.81] \\ 35 & 0 & 8 & 0 & 0.81[0.67,0.92] \\ 7 & 0 & 18 & 0 & 0.28[0.12,0.49] \\ 8 & 27 & 4 & 48 & 0.67[0.35,0.90] \\ 12 & 28 & 1 & 49 & 0.92[0.64,1.00] \\ 58 & 0 & 27 & 0 & 0.68[0.57,0.78] \\ 22 & 0 & 9 & 0 & 0.71[0.52,0.86] \\ 51 & 50 & 20 & 1389 & 0.72[0.60,0.82] \\ 37 & 4 & 44 & 1435 & 0.46[0.35,0.57] \\ 37 & 0 & 12 & 0 & 0.76[0.61,0.87] \\ 18 & 0 & 32 & 0 & 0.36[0.23,0.51] \\ 6 & 1 & 23 & 28 & 0.21[0.08,0.40] \\ 9 & 0 & 0 & 0 & 1.00[0.66,1.00] \\ 20 & 15 & 3 & 119 & 0.87[0.66,0.97] \\ 29 & 0 & 5 & 0 & 0.85[0.69,0.95] \\ 15 & 0 & 21 & 0 & 0.42[0.26,0.59] \\ 12 & 8 & 7 & 71 & 0.63[0.38,0.84] \\ 13 & 7 & 9 & 80 & 0.59[0.36,0.79] \\ 17 & 0 & 4 & 0 & 0.81[0.58,0.95] \\ 11 & 0 & 10 & 0 & 0.52[0.30,0.74] \\ 9 & 11 & 21 & 19 & 0.30[0.15,0.49] \\ 38 & 50 & 7 & 16 & 0.84[0.71,0.94] \\ 38 & 42 & 7 & 24 & 0.84[0.71,0.94] \\ 19 & 4 & 27 & 70 & 0.41[0.27,0.57]\end{array}$

Specificity $(95 \% \mathrm{Cl})$

Not estimable Not estimable Not estimable Not estimable

$0.54[0.42,0.66]$ Not estimable Not estimable 0.89 [0.81, 0.94] Not estimable

$0.86[0.73,0.94]$ Not estimable Not estimable Not estimable 0.99 [0.94, 1.00] Not estimable Not estimable Not estimable Not estimable Not estimable Not estimable Not estimable Not estimable Not estimable Not estimable Not estimable Not estimable $0.88[0.84,0.92]$

$0.86[0.71,0.95]$ Not estimable Not estimable Not estimable Not estimable Not estimable Not estimable $0.64[0.52,0.75]$

$0.64[0.52,0.74]$ Not estimable Not estimable $0.97[0.95,0.97]$ $1.00[0.99,1.00]$

Not estimable Not estimable $0.97[0.82,1.00]$ Not estimable $0.89[0.82,0.94]$

Not estimable Not estimable $0.90[0.81,0.96]$ $0.92[0.84,0.97]$

Not estimable Not estimable $0.63[0.44,0.80]$ $0.24[0.15,0.36]$ $0.36[0.25,0.49]$ $0.95[0.87,0.99]$
Sensitivity $(95 \% \mathrm{Cl}) \quad$ Specificity $(95 \% \mathrm{Cl})$

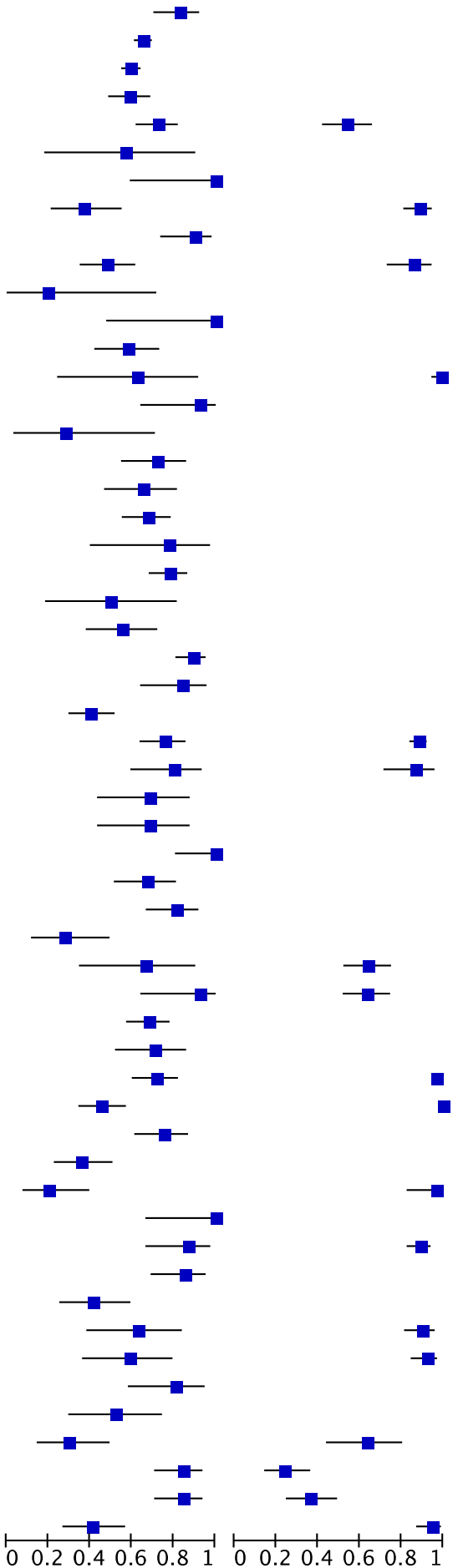

Fig. 1 Forest plot of all enrolled studies including IGRA test accuracy. Pooled sensitivity and specificity are 0.65 (95\%CI 0.63, 0.66 ) and 0.92 (95\%CI 0.91, 0.93), respectively 


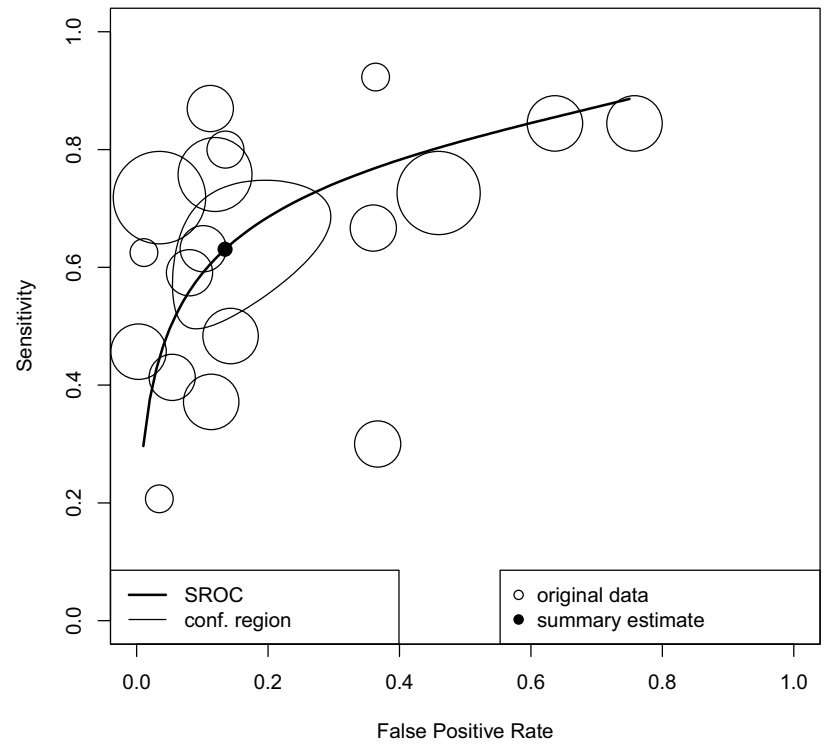

Fig. 2 Diagnostic accuracy of IGRAs in AIDS patients

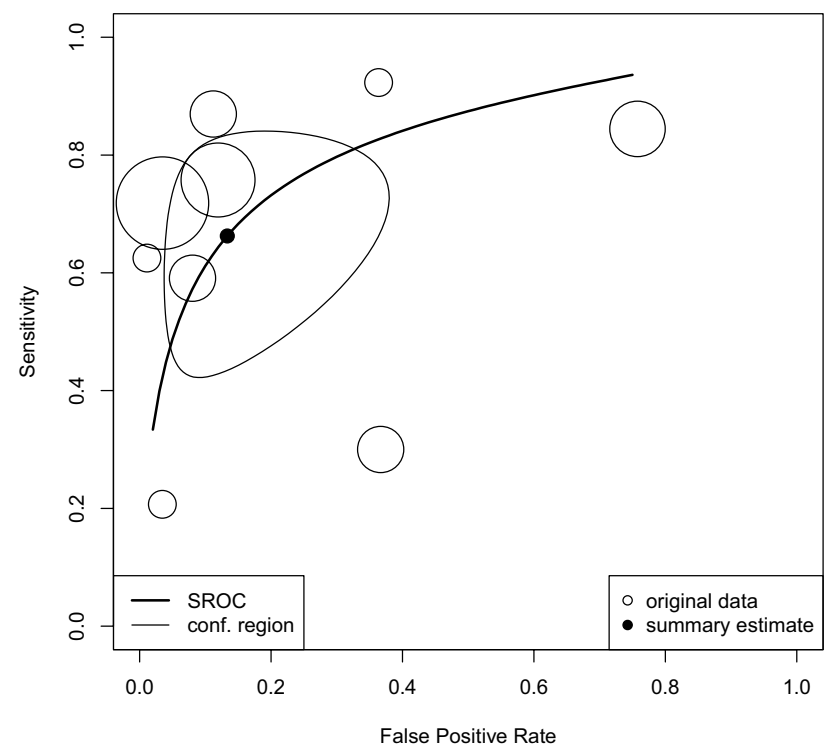

Fig. 3 Diagnostic accuracy of QFT in AIDS patients

0.66 (95\% CI $0.63,0.69)$ and 0.91 (95\% CI $0.90,0.92)$, respectively, in 27 studies of 3,369 cases of ATB disease in PLWHIV (Supplementary Figure S4).

\section{Diagnostic accuracy of T-SPOT in ATB}

Nine studies were included in the bivariate analysis of test accuracy with 2,397 samples that yielded a DOR of 10.0 (95\% CI $\left.3.8726 .03 ; I^{2}=2.6 \%\right)$ and an AUC of 0.729. This AUC suggested that T-SPOT had "good" diagnostic test accuracy for TB (Fig. 4) [16]. The summary estimates of sensitivity and specificity were 0.604 (95\%CI $0.481,0.715)$ and 0.862 (95\% CI $0.654,0.954)$, respectively. The univariate analysis showed that the sensitivity and specificity of T-SPOT were $0.65(95 \% \mathrm{CI} 0.62,0.68)$ and $0.93(0.92,0.94)$, respectively, in 16 studies of 2,810 patients of TB disease in PLWHIV (Supplementary Figure S5).

\section{Diagnostic accuracy of QFT and T-SPOT in LTBI}

The sensitivity of QFT and T-SPOT in the diagnosis of LTBI was $0.66(95 \%$ CI $0.63,0.70)$ and 0.60 (95\%CI $0.56,0.64)$, respectively (Supplementary Figure S6, S7). The specificity of QFT and T-SPOT was not estimable.

The risk of bias is shown in Supplementary Figure S8. There were 2 studies with unclear patient selection bias, and 7 studies had a high risk of a reference standard issue. No study showed bias in patient selection applicability concerns, index test, index test applicability concerns, reference standard applicability concerns, and flow and timing.

\section{Discussion}

The diagnostic test accuracies of the IGRA QFT and T-SPOT were systematically reviewed. Based on the analysis, QFT showed a better DOR and AUC than T-SPOT in the diagnosis of TB disease, and both of them showed "good" diagnostic accuracy. This systematic review and meta-analysis provided evidence supporting the use of IGRAs in the diagnosis of TB disease in PLWHIV, as in the current guidelines [1,61]. Although different

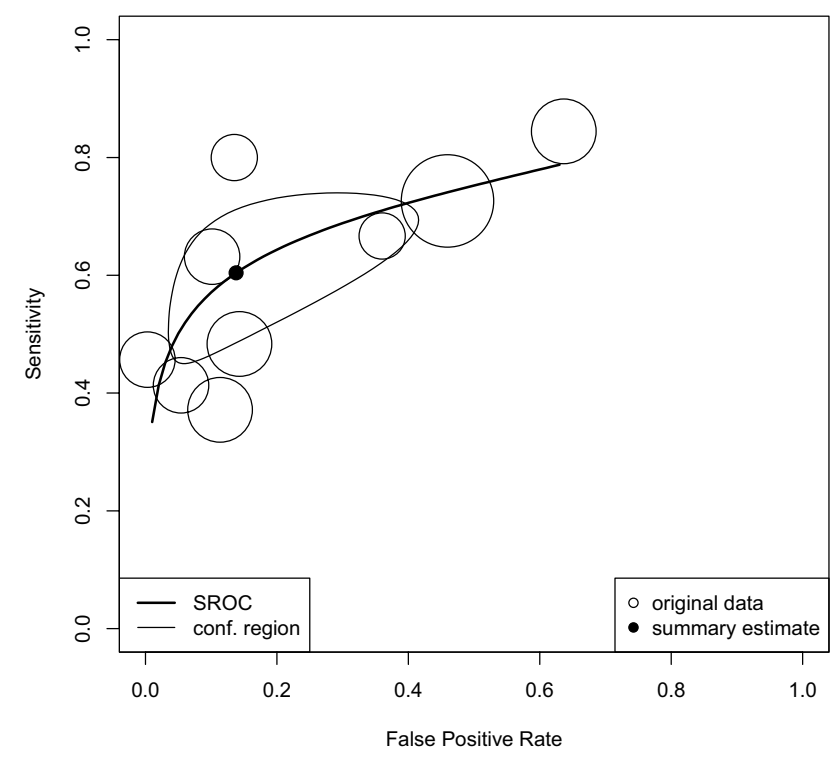

Fig. 4 Diagnostic accuracy of T-SPOT in AIDS patients 
diagnostic standards were used in seven studies discussing the sensitivity of IGRAs in PLWHIV, IGRAs showed a similar result, with an average sensitivity of 0.64 . It was difficult to use IGRAs to rule out a diagnosis of TB disease due to the low sensitivity in PLWHIV. No heterogeneity was observed in the bivariate analysis of IGRA and QFT, and only minimal heterogeneity was confirmed for T-SPOT, which supported the conclusion of this study.

The specificity of QFT and T-SPOT in diagnosis of ATB in PLWHIV was 0.867 (95\%CI 0.6830 .942$)$ and $0.862(95 \%$ CI $0.654,0.954)$, respectively. The pooled specificity of QFT, T-SPOT, and TST was: 79\% (95\%CI $75-82 \%), 59 \%$ (95\% CI 56-62\%), and $75 \%$ (95\% CI 72-78\%), respectively, reported by a previous study [8]. IGRAs and TST have similar (but poor) ability to identify patients with LTBI at risk of developing active TB disease. Both tests may be used in patients where the risk of progression to active TB disease is high and the disease sequelae potentially severe [62]. Compared with the general population, the sensitivity of IGRAs revealed a higher diagnostic accuracy. The improved specificity of IGRAs, however, may reduce the number of patients requiring preventative therapy.

QFT-Plus was more useful than QFT-GIT for the diagnosis of TB infection in all patients, including those who were elderly and/or immunocompromised [63]. Only one study showed data of the diagnostic accuracy in PLWHIV, and the results of 30/31 studies used data of QFT-GIT. However, so far, there was high agreement $(>95 \%)$ between the QFT-Plus and QFT-GIT [64, 65], QFT-plus might be better than T-SPOT in the diagnosis of TB disease in PLWHIV, but there is limited evidence to support this conclusion. IGRAs and TST are currently used to diagnose candidates for preventive LTBI therapy. The risk of TB disease in patients with an immunocompromised medical condition is greater than that in the general population. Although an increasing number of studies have demonstrated that IGRAs promoted the diagnosis of LTBI because of better specificity, there was still a high falsepositive rate in this study of PLWHIV.

There were several limitations in this study. First, almost all of the included studies were two-gate study designs, and a few studies discussed both sensitivity and specificity. The potential for a high risk of selection bias exists. Second, the tuberculosis burden was different in countries, and sub-group analysis was not conducted in different settings. Third, the number of CD4 T cells might affect IGRA test accuracy in PLWHIV. Due to different classifications, only a limited number of studies could perform sub-group analyses.

\section{Conclusion}

IGRA was useful in the diagnosis of TB disease in PLWHIV, and QFT showed a better tendency of DOR than T-SPOT. IGRAs showed a limited effect to rule-out LTBI in PLWHIV.

Supplementary Information The online version contains supplementary material available at https://doi.org/10.1007/s15010-022-01789-9.

Author contributions A.N. and H.C. contributed to the study search, quality check, data extraction, and drafting. M.T. worked on the study search, quality check, data extraction, and analysis as a principal investigator. S.A., D.U., N.H., S.K., and N.S. worked on the interpretation of data and the revision process. All the authors gave final approval.

Funding None.

Data availability statement The raw data are available by email on reasonable request to the corresponding author at nseki@med.teikyou.ac.jp.

\section{Declaration}

Conflicts of interest The authors declare that no conflicts of interests exist.

Open Access This article is licensed under a Creative Commons Attribution 4.0 International License, which permits use, sharing, adaptation, distribution and reproduction in any medium or format, as long as you give appropriate credit to the original author(s) and the source, provide a link to the Creative Commons licence, and indicate if changes were made. The images or other third party material in this article are included in the article's Creative Commons licence, unless indicated otherwise in a credit line to the material. If material is not included in the article's Creative Commons licence and your intended use is not permitted by statutory regulation or exceeds the permitted use, you will need to obtain permission directly from the copyright holder. To view a copy of this licence, visit http://creativecommons.org/licenses/by/4.0/.

\section{References}

1. Lewinsohn DM, Leonard MK, LoBue PA, Cohn DL, Daley CL, Desmond E, Keane J, Lewinsohn DA, Loeffler AM, Mazurek GH, et al. Official American Thoracic Society/Infectious Diseases Society of America/Centers for Disease Control and Prevention Clinical Practice Guidelines: diagnosis of tuberculosis in adults and children. Clin Infect Dis. 2017;64:e1-33. https://doi.org/10. 1093/cid/ciw694.

2. Sanogo B, Ouermi AS, Barro M, Millogo A, Ouattara ABI, Abdoul Salam O, Nacro B. Performance of a lymphocyte t interferon gamma test (Quantiferon-TB gold in tube) in the diagnosis of active tuberculosis in HIV-infected children. PLoS ONE. 2020;15:e0241789. https://doi.org/10.1371/journal.pone.0241789.

3. Gualano G, Mencarini P, Lauria FN, Palmieri F, Mfinanga S, Mwaba P, Chakaya J, Zumla A, Ippolito G. Tuberculin skin test - Outdated or still useful for Latent TB infection screening? Int J Infect Dis. 2019;80s:S20-s22. https://doi.org/10.1016/j.ijid.2019. 01.048 .

4. Mwaba P, Chakaya JM, Petersen E, Wejse C, Zumla A, Kapata N. Advancing new diagnostic tests for latent tuberculosis infection 
due to multidrug-resistant strains of Mycobacterium tuberculosis - End of the road? Int J Infect Dis. 2020;92s:S69-s71. https://doi. org/10.1016/j.ijid.2020.02.011.

5. Takwoingi Y, Whitworth H, Rees-Roberts M, Badhan A, Partlett C, Green N, Boakye A, Lambie H, Marongiu L, Jit M, et al. Interferon gamma release assays for Diagnostic Evaluation of Active tuberculosis (IDEA): test accuracy study and economic evaluation. Health Technol Assess. 2019;23:1-152. https://doi.org/10. 3310/hta23230.

6. Auguste P, Tsertsvadze A, Pink J, Court R, McCarthy N, Sutcliffe $\mathrm{P}$, Clarke A. Comparing interferon-gamma release assays with tuberculin skin test for identifying latent tuberculosis infection that progresses to active tuberculosis: systematic review and metaanalysis. BMC Infect Dis. 2017;17:200. https://doi.org/10.1186/ s12879-017-2301-4.

7. Zhou G, Luo Q, Luo S, Teng Z, Ji Z, Yang J, Wang F, Wen S, Ding $\mathrm{Z}$, Li L, et al. Interferon- $\gamma$ release assays or tuberculin skin test for detection and management of latent tuberculosis infection: a systematic review and meta-analysis. Lancet Infect Dis. 2020;20:1457-69. https://doi.org/10.1016/s1473-3099(20) 30276-0.

8. Sester M, Sotgiu G, Lange C, Giehl C, Girardi E, Migliori GB, Bossink A, Dheda K, Diel R, Dominguez J, et al. Interferon- $\gamma$ release assays for the diagnosis of active tuberculosis: a systematic review and meta-analysis. Eur Respir J. 2011;37:100-11. https:// doi.org/10.1183/09031936.00114810.

9. Caulfield AJ, Wengenack NL. Diagnosis of active tuberculosis disease: from microscopy to molecular techniques. J Clin Tuberc Other Mycobact Dis. 2016;4:33-43. https://doi.org/10.1016/j. jctube.2016.05.005.

10. Doan TN, Eisen DP, Rose MT, Slack A, Stearnes G, McBryde ES. Interferon-gamma release assay for the diagnosis of latent tuberculosis infection: a latent-class analysis. PLoS ONE. 2017;12: e0188631. https://doi.org/10.1371/journal.pone.0188631.

11. Leeflang MM, Deeks JJ, Takwoingi Y, Macaskill P. Cochrane diagnostic test accuracy reviews. Syst Rev. 2013;2:82. https://doi. org/10.1186/2046-4053-2-82.

12. University hospital Medical Information Network. https://upload. umin.ac.jp/cgi-bin/ctr/ctr_view_reg.cgi?recptno=R000052187. Accessed 1 Oct 2021.

13. Whiting PF, Rutjes AW, Westwood ME, Mallett S, Deeks JJ, Reitsma JB, Leeflang MM, Sterne JA, Bossuyt PM. QUADAS-2: a revised tool for the quality assessment of diagnostic accuracy studies. Ann Intern Med. 2011;155:529-36. https://doi.org/10. 7326/0003-4819-155-8-201110180-00009.

14. Carranza C, Pedraza-Sanchez S, de Oyarzabal-Mendez E, Torres M. Diagnosis for latent tuberculosis infection: new alternatives. Front Immunol. 2006;2020:11. https://doi.org/10.3389/fimmu. 2020.02006

15. Higgins J, Green S. Cochrane handbook for systematic reviews of interventions. Chichester: Wiley; 2008.

16. Jones CM, Athanasiou T. Summary receiver operating characteristic curve analysis techniques in the evaluation of diagnostic tests. Ann Thorac Surg. 2005;79:16-20. https://doi.org/10.1016/j.athor acsur.2004.09.040.

17. Higgins JP, Thompson SG, Deeks JJ, Altman DG. Measuring inconsistency in meta-analyses. BMJ. 2003;327:557-60. https:// doi.org/10.1136/bmj.327.7414.557.

18. Aabye MG, Ravn P, PrayGod G, Jeremiah K, Mugomela A, Jepsen M, Faurholt D, Range N, Friis H, Changalucha J, et al. The impact of HIV infection and CD4 cell count on the performance of an interferon gamma release assay in patients with pulmonary tuberculosis. PLoS ONE. 2009;4: e4220. https://doi.org/10.1371/journ al.pone. 0004220 .

19. Adams S, Ehrlich R, Baatjies R, Dendukuri N, Wang Z, Dheda $K$. Evaluating latent tuberculosis infection test performance using latent class analysis in a TB and HIV endemic setting. Int J Environ Res Public Health. 2019;16:2912. https://doi.org/10.3390/ ijerph16162912.

20. Cai R, Chen J, Guan L, Sun M, Sun Y, Shen Y, Zhang R, Liu L, $\mathrm{Lu}$ H. Relationship between T-SPOT. TB responses and numbers of circulating CD4+ T-cells in HIV infected patients with active tuberculosis. Biosci Trends. 2014;8:163-8.

21. Cattamanchi A, Ssewenyana I, Davis JL, Huang L, Worodria W, den Boon S, Yoo S, Andama A, Hopewell PC, Cao H. Role of interferon-gamma release assays in the diagnosis of pulmonary tuberculosis in patients with advanced HIV infection. BMC Infect Dis. 2010;10:75. https://doi.org/10.1186/1471-2334-10-75.

22. Chee CB, Gan SH, Khinmar KW, Barkham TM, Koh CK, Liang S, Wang YT. Comparison of sensitivities of two commercial gamma interferon release assays for pulmonary tuberculosis. J Clin Microbiol. 2008;46:1935-40. https://doi.org/10.1128/jcm.02403-07.

23. Chen J, Zhang R, Wang J, Liu L, Zheng Y, Shen Y, Qi T, Lu $\mathrm{H}$. Interferon-gamma release assays for the diagnosis of active tuberculosis in HIV-infected patients: a systematic review and meta-analysis. PLoS ONE. 2011;6: e26827. https://doi.org/10. 1371/journal.pone.0026827.

24. Clark SA, Martin SL, Pozniak A, Steel A, Ward B, Dunning J, Henderson DC, Nelson M, Gazzard B, Kelleher P. Tuberculosis antigen-specific immune responses can be detected using enzymelinked immunospot technology in human immunodeficiency virus (HIV)-1 patients with advanced disease. Clin Exp Immunol. 2007;150:238-44. https://doi.org/10.1111/j.1365-2249.2007. 03477.x.

25. Davies MA, Connell T, Johannisen C, Wood K, Pienaar S, Wilkinson KA, Wilkinson RJ, Zar HJ, Eley B, Beatty D, et al. Detection of tuberculosis in HIV-infected children using an enzyme-linked immunospot assay. AIDS. 2009;23:961-9. https://doi.org/10. 1097/QAD.0b013e32832956ad.

26. Dheda K, van Zyl-Smit RN, Meldau R, Meldau S, Symons G, Khalfey H, Govender N, Rosu V, Sechi LA, Maredza A, et al. Quantitative lung T cell responses aid the rapid diagnosis of pulmonary tuberculosis. Thorax. 2009;64:847-53. https://doi.org/10. 1136/thx.2009.116376.

27. Elzi L, Steffen I, Furrer H, Fehr J, Cavassini M, Hirschel B, Hoffmann M, Bernasconi E, Bassetti S, Battegay M. Improved sensitivity of an interferon-gamma release assay (T-SPOT.TB ${ }^{\mathrm{TM}}$ ) in combination with tuberculin skin test for the diagnosis of latent tuberculosis in the presence of HIV co-infection. BMC Infect Dis. 2011;11:319. https://doi.org/10.1186/1471-2334-11-319.

28. Fujita A, Ajisawa A, Harada N, Higuchi K, Mori T. Performance of a whole-blood interferon-gamma release assay with mycobacterium RD1-specific antigens among HIV-infected persons. Clin Dev Immunol. 2011;2011:325295. https://doi.org/10.1155/2011/ 325295.

29. Garcia-Elorriaga G, Martinez-Velazquez M, Gaona-Flores V, del Rey-Pineda G, Gonzalez-Bonilla C. Interferon gamma in patients with HIV/AIDS and suspicion or latent tuberculosis infection. Asian Pac J Trop Med. 2013;6:135-8. https://doi.org/10.1016/ s1995-7645(13)60009-7.

30. Hormi M, Guérin-El Khourouj V, Pommelet V, Jeljeli M, Pédron B, Diana JS, Faye A, Sterkers G. Performance of the QuantiFERON-TB gold assay among HIV-infected children with active tuberculosis in France. Pediatr Infect Dis J. 2018;37:339-44. https://doi.org/10.1097/inf.0000000000001774.

31. Idh J, Abate E, Westman A, Elias D, Janols H, Gelaw A, Getachew A, Alemu S, Aseffa A, Britton S, et al. Kinetics of the QuantiFERON (R)-TB gold in-tube test during treatment of patients with sputum smear-positive tuberculosis in relation to initial TST result and severity of disease. Scand J Infect Dis. 2010;42:650-7. https:// doi.org/10.3109/00365548.2010.482942. 
32. Jiang W, Shao L, Zhang Y, Zhang S, Meng C, Xu Y, Huang L, Wang Y, Wang Y, Weng X, et al. High-sensitive and rapid detection of Mycobacterium tuberculosis infection by IFN-gamma release assay among HIV-infected individuals in BCG-vaccinated area. BMC Immunol. 2009;10:31. https://doi.org/10.1186/ 1471-2172-10-31.

33. Jonnalagadda SR, Brown E, Lohman-Payne B, Wamalwa D, Farquhar C, John-Stewart GC. Predictive value of interferon-gamma release assays for postpartum active tuberculosis in HIV-1-infected women. Int J Tuberc Lung Dis. 2013;17:1552-7. https:// doi.org/10.5588/ijtld.13.0239.

34. Kabeer BSA, Sikhamani R, Raja A. Comparison of interferon gamma-inducible protein-10 and interferon gamma-based QuantiFERON TB Gold assays with tuberculin skin test in HIVinfected subjects. Diagn Microbiol Infect Dis. 2011;71:236-43. https://doi.org/10.1016/j.diagmicrobio.2011.07.012.

35. Kaswandani N, Nurul D. Performance of interferon gamma release assay and tuberculin skin test for TB diagnosis in HIV infected children. Pediatr Pulmonol. 2018;53:S160-1.

36. Khawcharoenporn T, Apisarnthanarak A, Phetsuksiri B, Rudeeaneksin J, Srisungngam S, Mundy LM. Tuberculin skin test and QuantiFERON-TB gold in-tube test for latent tuberculosis in Thai HIV-infected adults. Respirology. 2015;20:340-7. https:// doi.org/10.1111/resp.12442.

37. Klautau GB, da Mota NVF, Salles MJC, Burattini MN, Rodrigues DS. Interferon-gamma release assay as a sensitive diagnostic tool of latent tuberculosis infection in patients with HIV: a crosssectional study. BMC Infect Dis. 2018;18:585. https://doi.org/10. 1186/s12879-018-3508-8.

38. Kussen GM, Dalla-Costa LM, Rossoni A, Raboni SM. Interferongamma release assay versus tuberculin skin test for latent tuberculosis infection among HIV patients in Brazil. Braz J Infect Dis. 2016;20:69-75. https://doi.org/10.1016/j.bjid.2015.10.007.

39. LaCourse SM, Cranmer LM, Matemo D, Kinuthia J, Richardson BA, Horne DJ, John-Stewart G. Effect of pregnancy on interferon gamma release assay and tuberculin skin test detection of latent TB infection among HIV-infected women in a high burden setting. J Acquir Immune Defic Syndr. 2017;75:128-36. https://doi.org/ 10.1097/qai.0000000000001298.

40. Lavender T, Barrett A, Magee J, Ong E. Whole-blood interferongamma release assay in the diagnosis of active tuberculosis infection in HIV-infected and HIV-non-infected individuals: a five-year review of data. HIV Med. 2011;12:9-9.

41. Lee S, Lee JE, Kang JS, Lee SO, Lee SH. Long-term performance of the IGRA to predict and prevent active tuberculosis development in HIV-infected patients. Int $\mathbf{J}$ Tuberc Lung Dis. 2019;23:422-7. https://doi.org/10.5588/ijtld.18.0198.

42. Legesse M, Ameni G, Mamo G, Medhin G, Bjune G, Abebe F. Performance of QuantiFERON-TB Gold In-Tube (QFTGIT) for the diagnosis of Mycobacterium tuberculosis $(\mathrm{Mtb})$ infection in Afar Pastoralists, Ethiopia. BMC Infect Dis. 2010;10:354. https:// doi.org/10.1186/1471-2334-10-354.

43. Leidl L, Mayanja-Kizza H, Sotgiu G, Baseke J, Ernst M, Hirsch C, Goletti D, Toossi Z, Lange C. Relationship of immunodiagnostic assays for tuberculosis and numbers of circulating CD4+ T-cells in HIV infection. Eur Respir J. 2010;35:619-26. https://doi.org/ 10.1183/09031936.00045509.

44. Ling DI, Pai M, Davids V, Brunet L, Lenders L, Meldau R, Calligaro G, Allwood B, van Zyl-Smit R, Peter J, et al. Are interferon- $\gamma$ release assays useful for diagnosing active tuberculosis in a highburden setting? Eur Respir J. 2011;38:649-56. https://doi.org/10. 1183/09031936.00181610.

45. Lundtoft C, Awuah AA, Nausch N, Enimil A, Mayatepek E, Owusu-Dabo E, Jacobsen M. Alternative Quantiferon cytokines for diagnosis of children with active tuberculosis and HIV co-infection in Ghana. Med Microbiol Immunol. 2017;206:259_ 65. https://doi.org/10.1007/s00430-017-0501-6.

46. Markova R, Todorova Y, Drenska R, Elenkov I, Yankova M, Stefanova $\mathrm{D}$. Usefulness of interferon-gamma release assays in the diagnosis of tuberculosis infection in HIV-infected patients in Bulgaria. Biotechnol Biotechnol Equip. 2009;23:1103-8. https:// doi.org/10.1080/13102818.2009.10817622.

47. Oni T, Patel J, Gideon HP, Seldon R, Wood K, Hlombe Y, Wilkinson KA, Rangaka MX, Mendelson M, Wilkinson RJ. Enhanced diagnosis of HIV-1-associated tuberculosis by relating T-SPOT. TB and CD4 counts. Eur Respir J. 2010;36:594-600. https://doi. org/10.1183/09031936.00171509.

48. Petruccioli E, Chiacchio T, Navarra A, Vanini V, Cuzzi G, Cimaglia C, Codecasa LR, Pinnetti C, Riccardi N, Palmieri F, et al. Effect of HIV-infection on QuantiFERON-plus accuracy in patients with active tuberculosis and latent infection. J Infect. 2020;80:536-46. https://doi.org/10.1016/j.jinf.2020.02.009.

49. Pettit AC, Stout JE, Belknap R, Benson CA, Séraphin MN, Lauzardo M, Horne DJ, Garfein RS, Maruri F, Ho CS. Optimal testing choice and diagnostic strategies for latent tuberculosis infection among U.S.-born people living with HIV. Clin Infect Dis. 2020;73:e2278-84. https://doi.org/10.1093/cid/ciaa1135,10.1093/ $\mathrm{cid} / \mathrm{ciaa} 1135$.

50. Raby E, Moyo M, Devendra A, Banda J, De Haas P, Ayles H, Godfrey-Faussett P. The effects of HIV on the sensitivity of a whole blood IFN-gamma release assay in Zambian adults with active tuberculosis. PLoS ONE. 2008;3: e2489. https://doi.org/ 10.1371/journal.pone.0002489.

51. Rangaka MX, Gideon HP, Wilkinson KA, Pai M, Mwansa-Kambafwile J, Maartens G, Glynn JR, Boulle A, Fielding K, Goliath $\mathrm{R}$, et al. Interferon release does not add discriminatory value to smear-negative HIV-tuberculosis algorithms. Eur Respir J. 2012;39:163-71. https://doi.org/10.1183/09031936.00058911.

52. Sattah MV, Aye SS, Azen C, Kort JJ, Escalante P, Jones BE. Interferon-gamma release assay T-SPOT®.TB and HIV-related tuberculosis. Int J Tuberc Lung Dis. 2012;16:281-2. https://doi. org/10.5588/ijtld.11.0441.

53. Sauzullo I, Mengoni F, Scrivo R, Valesini G, Potenza C, Skroza N, Marocco R, Lichtner M, Vullo V, Mastroianni CM. Evaluation of QuantiFERON-TB gold in-tube in human immunodeficiency virus infection and in patient candidates for anti-tumour necrosis factor-alpha treatment. Int J Tuberc Lung Dis. 2010;14:834-40.

54. Sauzullo I, Mengoni F, Ermocida A, Massetti AP, D'Agostino C, Russo G, Salotti A, Falciano M, Vullo V, Mastroianni CM. Interferon-gamma release assay in HIV-infected patients with active tuberculosis: impact of antituberculous drugs on host immune response. New Microbiol. 2014;37:153-61.

55. Stavri H, Ene L, Popa GL, Duiculescu D, Murgoci G, Marica C, Ulea I, Cus G, Popa MI. Comparison of tuberculin skin test with a whole-blood interferon gamma assay and ELISA, in HIV positive children and adolescents with TB. Roum Arch Microbiol Immunol. 2009;68:14-9.

56. Tsiouris SJ, Coetzee D, Toro PL, Austin J, Stein Z, El-Sadr W. Sensitivity analysis and potential uses of a novel gamma interferon release assay for diagnosis of tuberculosis. J Clin Microbiol. 2006;44:2844-50. https://doi.org/10.1128/jcm.02411-05.

57. Vanini V, Petruccioli E, Gioia C, Cuzzi G, Orchi N, Rianda A, Alba L, Giancola ML, Conte A, Schininà V, et al. IP-10 is an additional marker for tuberculosis (TB) detection in HIV-infected persons in a low-TB endemic country. J Infect. 2012;65:49-59. https://doi.org/10.1016/j.jinf.2012.03.017.

58. Veldsman C, Kock MM, Rossouw T, Nieuwoudt M, Maeurer M, Hoosen AA, Ehlers MM. QuantiFERON-TB GOLD ELISA assay for the detection of Mycobacterium tuberculosis-specific antigens in blood specimens of HIV-positive patients in a high-burden 
country. FEMS Immunol Med Microbiol. 2009;57:269-73. https://doi.org/10.1111/j.1574-695X.2009.00610.x.

59. Vincenti D, Carrara S, Butera O, Bizzoni F, Casetti R, Girardi E, Goletti D. Response to region of difference 1 (RD1) epitopes in human immunodeficiency virus (HIV)-infected individuals enrolled with suspected active tuberculosis: a pilot study. Clin Exp Immunol. 2007;150:91-8. https://doi.org/10.1111/j.13652249.2007.03462.x.

60. Yu Y, Zhao X, Wang W, Wu H, Chen M, Hua W, Wang H, Wei T, Jiao Y, Sun G, et al. Diagnostic performance of interferon-gamma releasing assay in HIV-infected patients in China. PLoS ONE. 2013;8: e70957. https://doi.org/10.1371/journal.pone.0070957.

61. World Health Organization. Latent tuberculosis infection: updated and consolidated guidelines for programmatic management. Geneva: World Health Organization; 2018.

62. Bastian I, Coulter C. Position statement on interferon- $\gamma$ release assays for the detection of latent tuberculosis infection. Commun Dis Intell Q Rep. 2017;41:E322-e336.
63. Sotgiu G, Saderi L, Petruccioli E, Aliberti S, Piana A, Petrone L, Goletti D. QuantiFERON TB Gold Plus for the diagnosis of tuberculosis: a systematic review and meta-analysis. J Infect. 2019;79:444-53. https://doi.org/10.1016/j.jinf.2019.08.018.

64. Theel ES, Hilgart H, Breen-Lyles M, McCoy K, Flury R, Breeher LE, Wilson J, Sia IG, Whitaker JA, Clain J, et al. Comparison of the QuantiFERON-TB Gold Plus and QuantiFERON-TB Gold In-Tube Interferon Gamma Release Assays in Patients at Risk for Tuberculosis and in Health Care Workers. J Clin Microbiol. 2018;56:e00614-8. https://doi.org/10.1128/jcm.00614-18.

65. Pieterman ED, Liqui Lung FG, Verbon A, Bax HI, Ang CW, Berkhout J, Blaauw G, Brandenburg A, van Burgel ND, Claessen A, et al. A multicentre verification study of the QuantiFERON(®)-TB Gold Plus assay. Tuberculosis (Edinb). 2018;108:136-42. https:// doi.org/10.1016/j.tube.2017.11.014. 